Check for updates

Cite this: RSC Adv., 2018, 8, 5433

Received 24th November 2017

Accepted 4th January 2018

DOI: $10.1039 / c 7 r a 12766 a$

rsc.li/rsc-advances

\section{The synthesis of $a \mathrm{Bi}_{2} \mathrm{MoO}_{6} / \mathrm{Bi}_{4} \mathrm{~V}_{2} \mathrm{O}_{11}$ heterojunction photocatalyst with enhanced visible-light-driven photocatalytic activity $\dagger$}

\author{
Chol-Nam Ri, (iD *ab Song-Gol Kim, ${ }^{a}$ Kyong-Sik Ju, ${ }^{\mathrm{c}}$ Hyok-Su Ryo, ${ }^{\mathrm{d}}$ Chol-Ho Mun ${ }^{\mathrm{a}}$ \\ and U-Hyon Kim ${ }^{a}$
}

A novel $\mathrm{Bi}_{2} \mathrm{MoO}_{6} / \mathrm{Bi}_{4} \mathrm{~V}_{2} \mathrm{O}_{11}$ heterostructured photocatalyst was successfully fabricated using a facile onepot solvothermal method. This heterojunction consists of homogeneous dispersed $\mathrm{Bi}_{4} \mathrm{~V}_{2} \mathrm{O}_{11}$ nanocrystals anchored on the surface of $\mathrm{Bi}_{2} \mathrm{MoO}_{6}$ nanoflakes, endowing the heterojunction with nanosized interfacial contact. Based on the favorable interfacial contact, the band alignment at the heterojunction effectively facilitated photo-generated carrier transfer, which was verified by photoelectrochemical and photoluminescence measurements. Thereby, in contrast with pristine $\mathrm{Bi}_{2} \mathrm{MoO}_{6}$ and $\mathrm{Bi}_{4} \mathrm{~V}_{2} \mathrm{O}_{11}$, the assynthesized heterojunction with nanoscale contact exhibited significantly enhanced photocatalytic activity towards the degradation of $\mathrm{MB}$ and the reduction of $\mathrm{Cr}(\mathrm{vI})$. In addition, the as-fabricated $\mathrm{Bi}_{2} \mathrm{MoO}_{6} / \mathrm{Bi}_{4} \mathrm{~V}_{2} \mathrm{O}_{11}$ heterojunction exhibited good cycling stability for $\mathrm{MB}$ degradation after 4 cycles. Finally, a plausible photocatalytic mechanism for $M B$ degradation over the $\mathrm{Bi}_{2} \mathrm{MoO}_{6} / \mathrm{Bi}_{4} \mathrm{~V}_{2} \mathrm{O}_{11}$ heterojunction was discussed in detail. This work not only reports a highly efficient photocatalyst but also sheds light on the design and optimization of a heterojunction.

\section{Introduction}

In recent years, water pollution has become a serious problem all around the world. A large number of pollutants, such as organic dyes, heavy metal ions, drugs etc. are discharged into both industrial waste water and domestic sewage. Until now, the conventional water treatment methods such as adsorption, coagulation, microbial degradation, and ultra-filtration were commonly used to treat waste water, however, this approach has the disadvantage of low removal efficiency and difficulty in removing low concentrations of contaminants. ${ }^{1-3}$ As a kind of green energy technology, semiconductor photocatalytic technology can remove all kinds of pollutants under the irradiation of sunlight and thus, has attracted a large amount of attention. Photocatalysis possesses a number of advantages, such as the room-temperature oxidation of contaminants even at low concentrations, reduced secondary pollution, non-toxicity and low-cost, which is suitable for the degradation of

anstitute for Electronic Materials, Kim Il Sung University, Pyongyang, Democratic People's Republic of Korea

${ }^{b}$ School of Chemistry and Chemical Engineering, Harbin Institute of Technology, Harbin, 150001, China. E-mail: rcn906@yahoo.com

'Institute of Advanced Science, Kim Il Sung University, Pyongyang, Democratic People's Republic of Korea

${ }^{d}$ Faculty of Physics, Kim Il Sung University, Pyongyang, Democratic People's Republic of Korea

$\dagger$ Electronic supplementary information (ESI) available. See DOI: 10.1039/c7ra12766a contaminants. ${ }^{4,5}$ To date, titanium dioxide $\left(\mathrm{TiO}_{2}\right)$ is undoubtedly considered to be the most exceptional photocatalyst for solar energy conversion and environmental applications under UV illumination $(\lambda<400 \mathrm{~nm})$. As is well known, among the solar spectrum, ultraviolet-light makes up only less than $5 \%$, while visible-light (760 $\mathrm{nm}>\lambda>400 \mathrm{~nm}$ ) makes up approximately $40 \%$. However, the major drawback of $\mathrm{TiO}_{2}$ is the wide band gap $(3.2 \mathrm{eV})$, which greatly reduces the efficiency of solar energy utilization and limits its commercial applications. ${ }^{6,7}$ Therefore, over the past few decades, a great deal of effort has been made to exploit more efficient visible-light-responding photocatalysts in which Bi-based semiconductors have attracted a substantial amount of attention due to their peculiar electronic structure and the low cost of raw materials. ${ }^{8}$

Recently, as an example of a Bi-based semiconductor, $\mathrm{Bi}_{2} \mathrm{MoO}_{6}$ has been regarded as a promising photocatalyst because of its narrow band gap (2.5-2.8 eV), high chemical stability and non-toxicity. Unfortunately, the rapid recombination of photo-induced electron-hole pairs and sluggish charge transport in pristine $\mathrm{Bi}_{2} \mathrm{MoO}_{6}$ greatly restrict its photocatalytic activity., ${ }^{\mathbf{9} 10}$ To overcome the obstacles of rapid charge carrier recombination, many strategies have been developed, such as controlling the morphology, ${ }^{11}$ doping ${ }^{\mathbf{1 2}}$ and constructing a heterojunction. Among them, the method of constructing a heterojunction has been the most popular, since it can boost charge carrier separation and transfer efficiently originating from the as-introduced built-in electric field at the heterostructured interface. To date, different types of $\mathrm{Bi}_{2} \mathrm{MoO}_{6}$-based composite 
photocatalysts, such as $\mathrm{g}-\mathrm{C}_{3} \mathrm{~N}_{4} / \mathrm{Bi}_{2} \mathrm{MoO}_{6},{ }^{13} \mathrm{BiOCl} / \mathrm{Bi}_{2} \mathrm{MoO}_{6},{ }^{14}$ $\mathrm{BiOBr} / \mathrm{Bi}_{2} \mathrm{MoO}_{6},{ }^{15} \mathrm{BiOI} / \mathrm{Bi}_{2} \mathrm{MoO}_{6},{ }^{16} \mathrm{Bi}_{2} \mathrm{MoO}_{6} / \mathrm{TiO}_{2},{ }^{17} \alpha-\mathrm{Fe}_{2} \mathrm{O}_{3} /$ $\mathrm{Bi}_{2} \mathrm{MoO}_{6},{ }^{18} \mathrm{Bi}_{2} \mathrm{O}_{3} / \mathrm{Bi}_{2} \mathrm{MoO}_{6},{ }^{19} \mathrm{Bi}_{2} \mathrm{~S}_{3} / \mathrm{Bi}_{2} \mathrm{MoO}_{6}{ }^{20} \mathrm{CdS} / \mathrm{Bi}_{2} \mathrm{MoO}_{6}$ (ref. 21) $\mathrm{Bi}_{2} \mathrm{MoO}_{6} / \mathrm{Bi}_{2} \mathrm{WO}_{6}$ (ref. 22) etc. have been fabricated with enhanced photocatalytic efficiency.

Very recently, $\mathrm{Bi}_{4} \mathrm{~V}_{2} \mathrm{O}_{11}$ with a peculiar layered structure that has intrinsic oxygen vacancies in perovskite $\left(\mathrm{VO}_{3.5} \square_{0.5}\right)^{2-}(\square$ represents the intrinsic oxygen vacancies) slabs sandwiched between $\left(\mathrm{Bi}_{2} \mathrm{O}_{2}\right)^{2+}$ layers, has been considered as an excellent photocatalyst for oxygen evolution and water purification. ${ }^{23-25}$ Because of the narrow band gap $(\sim 2.1 \mathrm{eV})$ and excellent charge carrier transport originating from its unique crystalline structure, $\mathrm{Bi}_{4} \mathrm{~V}_{2} \mathrm{O}_{11}$ has been employed to construct heterojunction photocatalysts, such as $\mathrm{BiVO}_{4} / \mathrm{Bi}_{4} \mathrm{~V}_{2} \mathrm{O}_{11}$ (ref. 26) and $\mathrm{Bi}_{24} \mathrm{O}_{31} \mathrm{Br}_{10} / \mathrm{Bi}_{4} \mathrm{~V}_{2} \mathrm{O}_{11} \cdot{ }^{27}$ All of above heterojunctions realize considerably enhanced photocatalytic activity due to the effective separation and transfer of photo-induced charge carriers. However, to the best of our knowledge, the construction of a $\mathrm{Bi}_{2} \mathrm{MoO}_{6} / \mathrm{Bi}_{4} \mathrm{~V}_{2} \mathrm{O}_{11}$ heterojunction has not been reported, which might enhance the photocatalytic properties of $\mathrm{Bi}_{2} \mathrm{MoO}_{6}$ considerably.

In this study, a $\mathrm{Bi}_{2} \mathrm{MoO}_{6} / \mathrm{Bi}_{4} \mathrm{~V}_{2} \mathrm{O}_{11}$ heterojunction was fabricated using a one-pot solvothermal method. This heterojunction was constructed from $\mathrm{Bi}_{4} \mathrm{~V}_{2} \mathrm{O}_{11}$ nanocrystals anchored on the $\mathrm{Bi}_{2} \mathrm{MoO}_{6}$ nanoflakes surface, achieving a nanosized interfacial contact. The photocatalytic performance of the asfabricated pristine $\mathrm{Bi}_{2} \mathrm{MoO}_{6}, \mathrm{Bi}_{4} \mathrm{~V}_{2} \mathrm{O}_{11}$ and different $\mathrm{Bi}_{2} \mathrm{MoO}_{6}$ / $\mathrm{Bi}_{4} \mathrm{~V}_{2} \mathrm{O}_{11}$ heterojunctions was evaluated by the photocatalytic degradation of methylene blue (MB) and photocatalytic reduction of $\mathrm{Cr}(\mathrm{vI})$ under visible-light illumination. The results indicated that the $\mathrm{Bi}_{2} \mathrm{MoO}_{6} / \mathrm{Bi}_{4} \mathrm{~V}_{2} \mathrm{O}_{11}$ heterojunction exhibited superior photocatalytic activity than pristine $\mathrm{Bi}_{2} \mathrm{MoO}_{6}$ and $\mathrm{Bi}_{4} \mathrm{~V}_{2} \mathrm{O}_{11}$. Furthermore, the as-fabricated $\mathrm{Bi}_{2} \mathrm{MoO}_{6} / \mathrm{Bi}_{4} \mathrm{~V}_{2} \mathrm{O}_{11}$ heterojunction exhibited good cycling stability for MB degradation after 4 cycles. Finally, the enhanced photocatalytic mechanism of the $\mathrm{Bi}_{2} \mathrm{MoO}_{6} / \mathrm{Bi}_{4} \mathrm{~V}_{2} \mathrm{O}_{11}$ heterojunction has also been discussed.

\section{Experimental}

\subsection{Photocatalysts preparation}

All chemicals reagents were received from Aladdin Chemical Co. Ltd. and used without further purification.

$2 \mathrm{mmol}$ of $\mathrm{Bi}\left(\mathrm{NO}_{3}\right)_{3} \cdot 5 \mathrm{H}_{2} \mathrm{O}$ was added into $15 \mathrm{~mL}$ of ethylene glycol and magnetically stirred in a water bath at $80^{\circ} \mathrm{C}$ to form a clear solution. Then, appropriate stoichiometric amounts of $\left(\mathrm{NH}_{4}\right)_{6} \mathrm{Mo}_{7} \mathrm{O}_{24} \cdot 4 \mathrm{H}_{2} \mathrm{O}$ and $\mathrm{NH}_{4} \mathrm{VO}_{3}$ were added into the abovementioned bismuth nitrate solution, which was continuously stirred for $20 \mathrm{~min}$ at $80{ }^{\circ} \mathrm{C}$ to obtain a transparent solution. Subsequently, the $\mathrm{pH}$ of the above solution was adjusted to about 8 by the slow dropwise addition of $2 \mathrm{M}$ sodium hydroxide solution. Then, the abovementioned solution was poured into a $25 \mathrm{~mL}$ Teflon-lined stainless autoclave, which was subsequently sealed and maintained at $160{ }^{\circ} \mathrm{C}$ for $16 \mathrm{~h}$ in an oven. After the reactor cooled down to room temperature, the asobtained product was centrifuged three times using water and absolute ethanol.
Finally, the photocatalyst was obtained after drying at $80{ }^{\circ} \mathrm{C}$ in air for $4 \mathrm{~h}$. According to the abovementioned method, $\mathrm{Bi}_{2} \mathrm{MoO}_{6} / \mathrm{Bi}_{4} \mathrm{~V}_{2} \mathrm{O}_{11}$ heterojunction photocatalysts with different molar amounts of $\mathrm{Mo}$ and $\mathrm{V}$ at $0.2 \mathrm{mmol}$ and $0.8 \mathrm{mmol}$ (denoted as BMV-28), $0.4 \mathrm{mmol}$ and $0.6 \mathrm{mmol}$ (denoted as BMV46), $0.5 \mathrm{mmol}$ and $0.5 \mathrm{mmol}$ (denoted as BMV-55), and $0.6 \mathrm{mmol}$ and $0.4 \mathrm{mmol}$ (denoted as BMV-64), respectively, were prepared. In addition, pristine $\mathrm{Bi}_{2} \mathrm{MoO}_{6}$ and $\mathrm{Bi}_{4} \mathrm{~V}_{2} \mathrm{O}_{11}$ were also fabricated for the purpose of comparison.

\subsection{Characterization}

The crystalline structures of the as-fabricated samples were analyzed using X-ray diffraction (XRD) on a Rigaku D/max-2000 diffractometer with $\mathrm{Cu} K \alpha$ radiation $(\lambda=1.5406 \AA)$ in the range of $2 \vartheta=20-90^{\circ}$ at a scanning rate of $4{ }^{\circ} \mathrm{C} \min ^{-1}$ with a scan width of $0.02^{\circ}$. The morphology of the samples was observed using field emission scanning electron microscopy (FE-SEM, HELIOS NanoLab 600i) at an accelerating voltage of $20 \mathrm{kV}$. The transmission electron microscopy (TEM) and highresolution TEM (HRTEM) analyses were carried out on a JEM2100 transmission electron microscope at an accelerating voltage of $200 \mathrm{kV}$. The X-ray photoelectron spectroscopy (XPS) was conducted on a Thermo Scientific ESCALAB 250Xi X-ray photoelectron spectrometer coupled with a pass energy of $20.00 \mathrm{eV}$ and an $\mathrm{Al} \mathrm{K} \alpha$ excitation source (1486.6 eV). The UV-vis diffuse reflectance spectra (DRS) were obtained on a spectrophotometer (HITACHI UH-4150) using $\mathrm{BaSO}_{4}$ as the reflectance standard. Photoluminescence (PL) analysis was accomplished on a HORIBA FluoroMax-4.

\subsection{Photocatalytic activity and photoelectrochemical measurements}

The photocatalytic performance of the as-fabricated samples was evaluated by the degradation of methylene blue (MB) and reduction of $\mathrm{Cr}(\mathrm{vI})$ under visible-light illumination using a $300 \mathrm{~W}$ Xe lamp (Trusttech PLS-SXE 300, Beijing) with a UV cutoff filter $(\lambda \geq 400 \mathrm{~nm})$. In a typical photocatalytic process, $0.05 \mathrm{~g}$ of the as-fabricated sample was added into $100 \mathrm{~mL}$ of $\mathrm{MB}$ solution $\left(10 \mathrm{mg} \mathrm{L}^{-1}\right)$ or $\mathrm{Cr}(\mathrm{vI})$ solution $\left(10 \mathrm{mg} \mathrm{L}^{-1}\right.$, which was based on $\mathrm{Cr}$ in a dilute $\mathrm{K}_{2} \mathrm{Cr}_{2} \mathrm{O}_{7}$ solution). The photocatalyst was dispersed in the above solution under ultrasonic treatment for $10 \mathrm{~min}$, and the mixed solution was magnetically stirred in the dark for $30 \mathrm{~min}$ to achieve an adsorption-desorption equilibrium between the photocatalyst and the pollutants. When the photodegradation experiment began, $4 \mathrm{~mL}$ of the solution was collected from the suspension at fixed-time intervals, centrifuged at $10^{4} \mathrm{rpm}$ for $5 \mathrm{~min}$ to remove catalyst powders, and the $\mathrm{MB}$ and $\mathrm{Cr}(\mathrm{vI})$ concentrations were determined using a HITACHI UH-5300 UV-vis spectrometer at 664 and $352 \mathrm{~nm}$, respectively. The photoelectrochemical measurements were carried out on a CHI604C electrochemical workstation using a standard three-compartment cell with the $\mathrm{Bi}_{4} \mathrm{~V}_{2} \mathrm{O}_{11}, \mathrm{Bi}_{2} \mathrm{MoO}_{6}$ and $\mathrm{Bi}_{2} \mathrm{MoO}_{6} / \mathrm{Bi}_{4} \mathrm{~V}_{2} \mathrm{O}_{11}$ samples coated on FTO glass used as the working electrode, a piece of Pt sheet as the counter electrode, standard $\mathrm{Ag} / \mathrm{AgCl}$ in saturated $\mathrm{KCl}$ as the reference electrode, and a $0.5 \mathrm{M} \mathrm{Na} \mathrm{SO}_{4}$ aqueous solution as the electrolyte. 
Converting between the measured potential (vs. $\mathrm{Ag} / \mathrm{AgCl}$ ) and NHE was achieved using eqn (1). ${ }^{28}$

$$
E_{\mathrm{NHE}}=E_{\mathrm{Ag} / \mathrm{AgCl}}+0.1976\left(25^{\circ} \mathrm{C}\right)
$$

The light source employed was a $300 \mathrm{~W}$ Xe lamp. The Mottschottky measurements were carried out at a frequency of $100 \mathrm{~Hz}$ and an amplitude of $10 \mathrm{mV}$.

\section{Results and discussion}

Fig. 1 shows the XRD patterns of the as-prepared pristine $\mathrm{Bi}_{2} \mathrm{MoO}_{6}$ and $\mathrm{Bi}_{4} \mathrm{~V}_{2} \mathrm{O}_{11}$ samples, and the BMV-55 composite sample. The diffraction peaks of the pristine $\mathrm{Bi}_{2} \mathrm{MoO}_{6}$ and $\mathrm{Bi}_{4} \mathrm{~V}_{2} \mathrm{O}_{11}$ samples can be well indexed to the orthorhombic phase $\mathrm{Bi}_{2} \mathrm{MoO}_{6}$ (JCPDS No. 72-1524) and the orthorhombic phase $\mathrm{Bi}_{4} \mathrm{~V}_{2} \mathrm{O}_{11}$ (JCPDS No. 42-0135), respectively. The XRD pattern of the BMV-55 composite contains both $\mathrm{Bi}_{2} \mathrm{MoO}_{6}$ and $\mathrm{Bi}_{4} \mathrm{~V}_{2} \mathrm{O}_{11}$ phases, indicating the coexistence of the two phases in the BMV-55 composite in which the extremely weak diffraction intensity of $\mathrm{Bi}_{4} \mathrm{~V}_{2} \mathrm{O}_{11}$ can be ascribed to its tiny size and uniform dispersion on the surface of $\mathrm{Bi}_{2} \mathrm{MoO}_{6}$. In addition, the XRD patterns of the BMV-28, BMV-46 and BMV-64 samples are shown in Fig. S1 in the ESI. $\dagger$ It can be seen that the diffraction peaks of BMV-28 and BMV-46 samples belong to the characteristic peaks of $\mathrm{Bi}_{4} \mathrm{~V}_{2} \mathrm{O}_{11}$, while no peaks corresponding to $\mathrm{Bi}_{2} \mathrm{MoO}_{6}$ can be detected, which might be attributed to the relatively lower content of $\mathrm{Bi}_{2} \mathrm{MoO}_{6}$ in the samples. Meanwhile, the diffraction peaks of BMV-64 samples correspond to those of $\mathrm{Bi}_{4} \mathrm{~V}_{2} \mathrm{O}_{11}$; however, the peak intensities are significantly weakened relative to those of pristine $\mathrm{Bi}_{4} \mathrm{~V}_{2} \mathrm{O}_{11}$. The morphology and microstructure of the samples are investigated using SEM, TEM and HRTEM. Fig. 2 shows the SEM images of the as-fabricated samples. The FESEM image in Fig. 2a shows that pristine $\mathrm{Bi}_{2} \mathrm{MoO}_{6}$ possesses an irregular flake-like morphology with a thickness of ca. $55 \mathrm{~nm}$. In contrast, pristine $\mathrm{Bi}_{4} \mathrm{~V}_{2} \mathrm{O}_{11}$ (Fig. 2b) displays hierarchical microspheres with diameters of

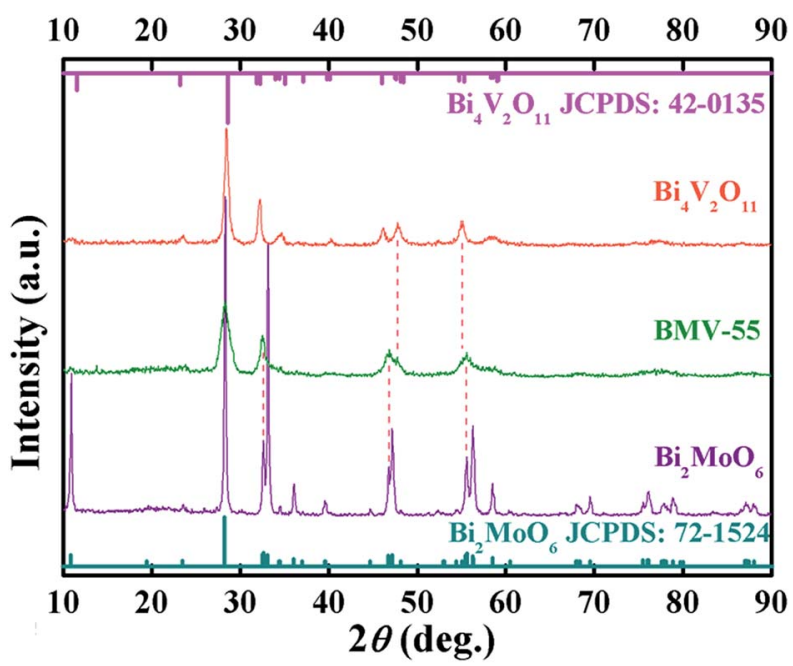

Fig. 1 The XRD patterns of pristine $\mathrm{Bi}_{2} \mathrm{MoO}_{6}$ and $\mathrm{Bi}_{4} \mathrm{~V}_{2} \mathrm{O}_{11}$ samples and the BMV-55 composite.

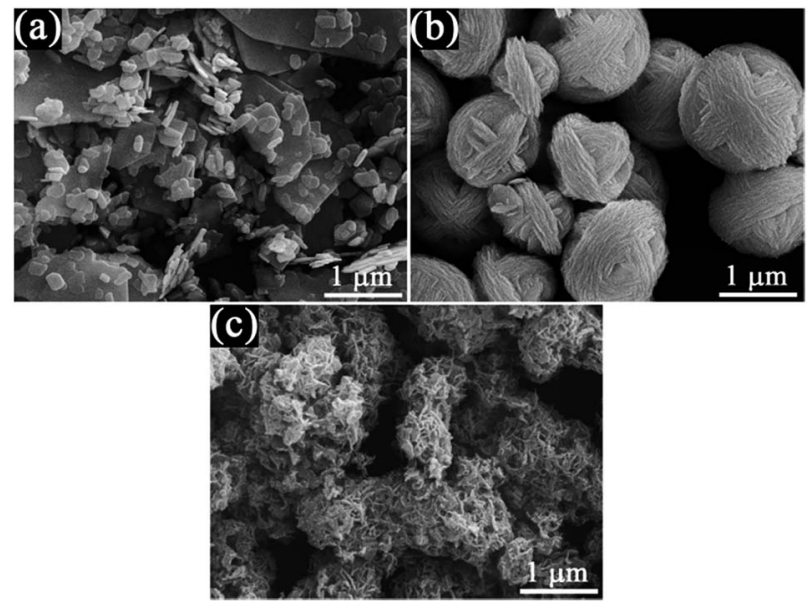

Fig. 2 FESEM images of (a) pristine $\mathrm{Bi}_{2} \mathrm{MoO}_{6}$, (b) pristine $\mathrm{Bi}_{4} \mathrm{~V}_{2} \mathrm{O}_{11}$ and (c) the BMV-55 composite.

approximately 1-2 $\mu \mathrm{m}$. In addition, Fig. $2 \mathrm{c}$ shows the morphology of the BMV-55 composite, showing that the BMV-55 composite has a fluffy structure stacked in a disorderly manner by the nanoflakes. Moreover, the SEM images of the BMV-28, BMV-46 and BMV-64 samples are shown in Fig. S2 in the ESI. $\uparrow$ To obtain a more detailed structural information about the BMV-55 composite, TEM analysis has been carried out. The TEM images of the BMV-55 composite are shown in Fig. 3. The TEM image of the BMV-55 composite at low magnification (Fig. 3a) illustrates that the BMV-55 composite is comprised of nanoflakes with a thickness of about $10 \mathrm{~nm}$ and length of about 100-200 nm, which is consistent with the SEM results described above. Interestingly, as observed from the magnified TEM image (Fig. 3b), nanocrystals with a size of ca. $10 \mathrm{~nm}$ are

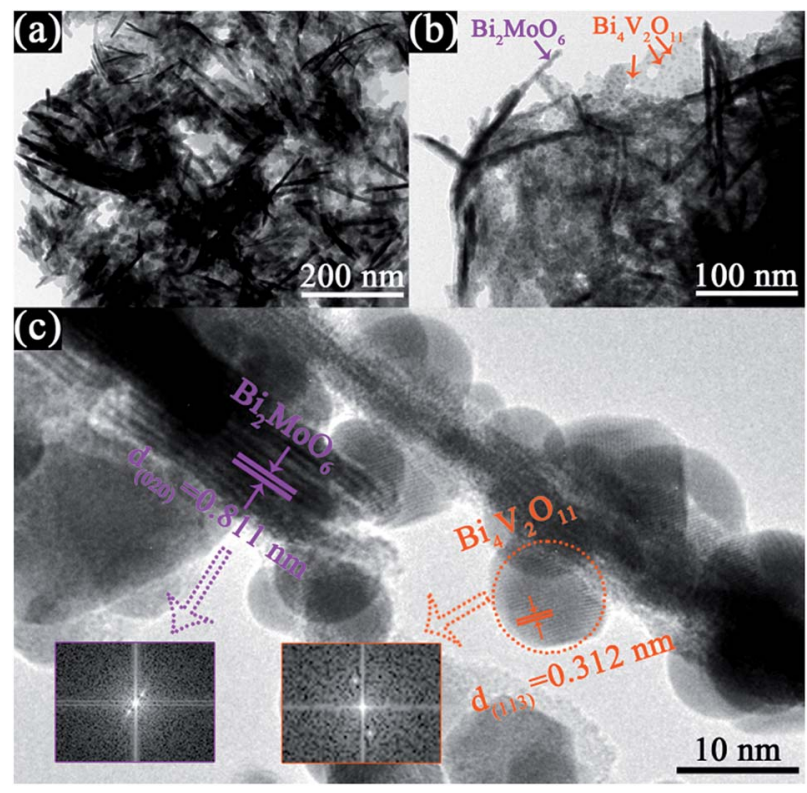

Fig. 3 TEM images of the BMV-55 composite. The (a) TEM image at low magnification, (b) magnified TEM image, and (c) HRTEM image of the BMV-55 composite. 
homogeneously dispersed and tightly adhered to the surface of the nanoflakes. By observing the HRTEM image of the BMV-55 composite (Fig. 3c), it can be further confirmed that the nanoflakes are $\mathrm{Bi}_{2} \mathrm{MoO}_{6}$ and the as-anchored nanocrystals are $\mathrm{Bi}_{4} \mathrm{~V}_{2} \mathrm{O}_{11}$ because the observed interplanar spacings of $0.811 \mathrm{~nm}$ and $0.312 \mathrm{~nm}$ correspond well to the (020) plane of the orthorhombic $\mathrm{Bi}_{2} \mathrm{MoO}_{6}$ and the (113) plane of the orthorhombic $\mathrm{Bi}_{4} \mathrm{~V}_{2} \mathrm{O}_{11}$, respectively. These results suggest that the $\mathrm{Bi}_{4} \mathrm{~V}_{2} \mathrm{O}_{11}$ nanocrystals are embedded on the $\mathrm{Bi}_{2} \mathrm{MoO}_{6}$ nanoflakes in the BMV-55 composite, forming a $\mathrm{Bi}_{2} \mathrm{MoO}_{6} / \mathrm{Bi}_{4} \mathrm{~V}_{2} \mathrm{O}_{11}$ heterojunction with a nanosized interfacial contact. With the aim of further verifying the coexistence of $\mathrm{Bi}_{2} \mathrm{MoO}_{6}$ and $\mathrm{Bi}_{4} \mathrm{~V}_{2} \mathrm{O}_{11}$, surface electronic states analysis of the BMV-55 composite have been performed using the X-ray photoelectron spectroscopy (XPS). Fig. 4 shows the high-resolution XPS spectra of the asfabricated BMV-55 composite photocatalyst. The full survey spectra and C 1s spectra of BMV-55 are shown in Fig. S3 in the ESI. $\dagger$

The peak positions in all of the XPS spectra were calibrated using the $\mathrm{C}$ 1s peak $(284.6 \mathrm{eV})$ as the reference. First, the two characteristic peaks located at 164.5 and $159.1 \mathrm{eV}$ in the $\mathrm{Bi}$ 4f spectra (Fig. 4a) were assigned to $\mathrm{Bi} 4 \mathrm{f}_{5 / 2}$ and $\mathrm{Bi} 4 \mathrm{f}_{7 / 2}$, respectively, which corresponded to $\mathrm{Bi}^{3+} .{ }^{29}$ Then, in the Mo $3 \mathrm{~d}$ XPS spectra (Fig. 4b), the binding energies for Mo $3 \mathrm{~d}_{3 / 2}$ and Mo $3 \mathrm{~d}_{5 / 2}$ located at 235.5 and $232.4 \mathrm{eV}$, respectively were assigned to $\mathrm{Mo}^{6+}$ in $\mathrm{Bi}_{2} \mathrm{MoO}_{6} \cdot{ }^{9,29}$ Furthermore, for the $\mathrm{V} 2 \mathrm{p}$ peaks (Fig. $4 \mathrm{c}$ ), the two peaks located at 524.1 and $516.7 \mathrm{eV}$ were assigned to $\mathrm{V}$ $2 \mathrm{p}_{1 / 2}$ and $\mathrm{V} 2 \mathrm{p}_{3 / 2}$, respectively and belonged to $\mathrm{V}^{5+}$ in $\mathrm{Bi}_{4} \mathrm{~V}_{2} \mathrm{O}_{11} \cdot{ }^{27,30}$ Moreover, as shown in Fig. $4 \mathrm{~d}$, the $\mathrm{O}$ 1s spectra could be divided into three peaks, and the binding energies located at 529.8, 530.3 and 531.2 eV could be assigned to the lattice oxygen in $\mathrm{Bi}-\mathrm{O},{ }^{13}$ lattice oxygen in $\mathrm{Mo}-\mathrm{O},{ }^{18}$ and intrinsic oxygen vacancy $\left(V_{\mathrm{o}}\right)$ in $\mathrm{Bi}_{4} \mathrm{~V}_{2} \mathrm{O}_{11},{ }^{31}$ respectively. The XPS results further indicated the simultaneous existence of $\mathrm{Bi}_{2} \mathrm{MoO}_{6}$ and $\mathrm{Bi}_{4} \mathrm{~V}_{2} \mathrm{O}_{11}$ species in the BMV-55 composite photocatalyst. In a bid to investigate the optical absorption capacity of the asprepared photocatalysts, UV-vis diffuse reflection spectra (DRS) analysis was carried out and is displayed in Fig. 5. As can
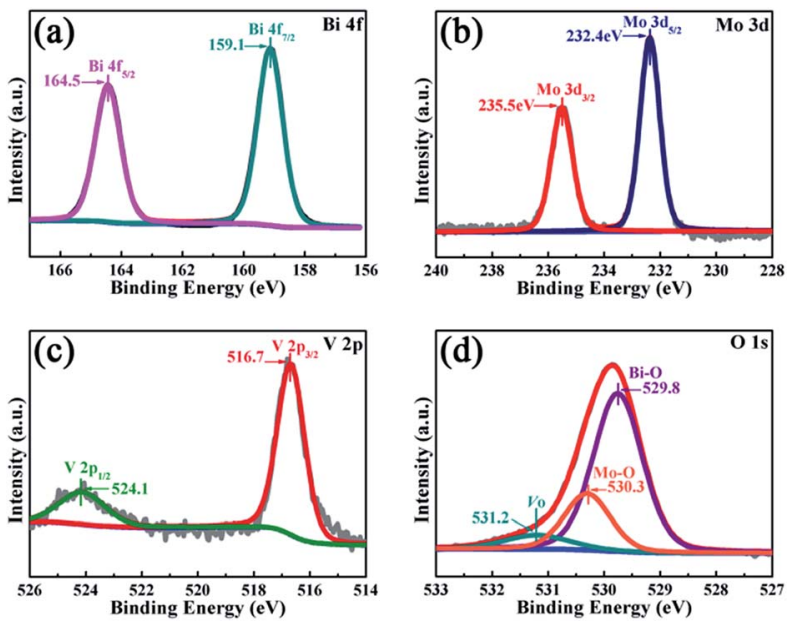

Fig. 4 The XPS spectra of the BMV-55 composite: (a) Bi 4f, (b) Mo 3d, (c) $\vee 2 p$, and (d) $\bigcirc 1 \mathrm{~s}$. be seen from Fig. $5 \mathrm{a}$, the absorption edges of pristine $\mathrm{Bi}_{2} \mathrm{MoO}_{6}$, $\mathrm{Bi}_{4} \mathrm{~V}_{2} \mathrm{O}_{11}$ and the BMV-55 composite were observed at about 475, 624 and $600 \mathrm{~nm}$, respectively. Obviously, the absorption edge of the BMV-55 composite exhibited a red shift compared with that of pristine $\mathrm{Bi}_{2} \mathrm{MoO}_{6}$, which illustrated that the introduction of $\mathrm{Bi}_{4} \mathrm{~V}_{2} \mathrm{O}_{11}$ was conducive to enhancing the light absorption capacity of the BMV-55 composite. In addition, the band gaps of pristine $\mathrm{Bi}_{2} \mathrm{MoO}_{6}$ and $\mathrm{Bi}_{4} \mathrm{~V}_{2} \mathrm{O}_{11}$ were calculated using the Kubelka-Munk function (eqn (2)). ${ }^{32}$

$$
\alpha h \nu=A\left(h \nu-E_{\mathrm{g}}\right)^{n / 2}
$$

where $\alpha, h, \nu, A$, and $E_{\mathrm{g}}$ represent the absorption coefficient, Planck constant, light frequency, a constant, and band gap, respectively. In this function, $n$ is determined by the type of optical transition in the semiconductor. Generally, $n=1$ for direct transition and $n=4$ for indirect transition. Both $\mathrm{Bi}_{2} \mathrm{MoO}_{6}$ (ref. 21) and $\mathrm{Bi}_{4} \mathrm{~V}_{2} \mathrm{O}_{11}$ (ref. 33) are direct transition semiconductors and their $n$ value is 1 . Fig. $5 \mathrm{~b}$ shows the curves of $(\alpha h \nu)^{2} v s$. photon energy $(h \nu)$ of the pristine $\mathrm{Bi}_{2} \mathrm{MoO}_{6}$ and $\mathrm{Bi}_{4} \mathrm{~V}_{2} \mathrm{O}_{11}$ samples, which indicate that the band gaps of pristine $\mathrm{Bi}_{2} \mathrm{MoO}_{6}$ and $\mathrm{Bi}_{4} \mathrm{~V}_{2} \mathrm{O}_{11}$ are approximately 2.62 and $2.02 \mathrm{eV}$, respectively. The photocatalytic performance of the as-prepared photocatalysts was evaluated by the degradation of $\mathrm{MB}$ in the presence of $\mathrm{H}_{2} \mathrm{O}_{2}(0.1 \mathrm{~mL})$ under visible light irradiation. Fig. $6 \mathrm{a}$ presents the variation plots of $\mathrm{MB}$ concentration $\left(C / C_{0}\right)$ versus light irradiation time for the different $\mathrm{Bi}_{2} \mathrm{MoO}_{6} / \mathrm{Bi}_{4} \mathrm{~V}_{2} \mathrm{O}_{11}$ composites along with the pristine $\mathrm{Bi}_{2} \mathrm{MoO}_{6}$ and $\mathrm{Bi}_{4} \mathrm{~V}_{2} \mathrm{O}_{11}$ samples. As shown in the figure, the degradation rate of $\mathrm{MB}$ over the pristine $\mathrm{Bi}_{2} \mathrm{MoO}_{6}$ and $\mathrm{Bi}_{4} \mathrm{~V}_{2} \mathrm{O}_{11}$ samples reached $c a$. $83 \%$ and $46 \%$ after $60 \mathrm{~min}$, respectively. Among the asfabricated $\mathrm{Bi}_{2} \mathrm{MoO}_{6} / \mathrm{Bi}_{4} \mathrm{~V}_{2} \mathrm{O}_{11}$ composites, with the exception of BMV-55, there was no obvious enhancement in the photocatalytic efficiency over the three other samples (BMV-28, BMV46 and $\mathrm{BMV}-64$ ) compared with that of pristine $\mathrm{Bi}_{2} \mathrm{MoO}_{6}$. In contrast, the BMV-55 composite exhibited a significantly enhanced photocatalytic activity towards the degradation of $\mathrm{MB}$ among the samples and the photodegradation rate of $\mathrm{MB}$ achieved was almost $100 \%$ after 15 min of light irradiation. Fig. 6b-d display the UV-vis absorption spectra of the degradation solution obtained at certain time intervals over the BMV55 composite and pristine $\mathrm{Bi}_{2} \mathrm{MoO}_{6}$ and $\mathrm{Bi}_{4} \mathrm{~V}_{2} \mathrm{O}_{11}$ samples, respectively, which showed the superiority of the BMV-55 composite for $\mathrm{MB}$ degradation relative to those of pristine (a)

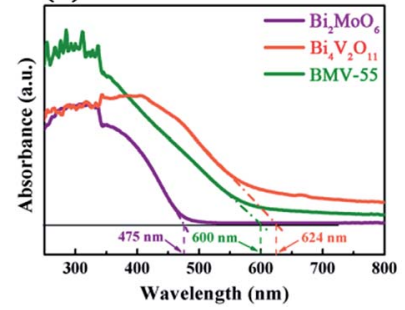

(b)

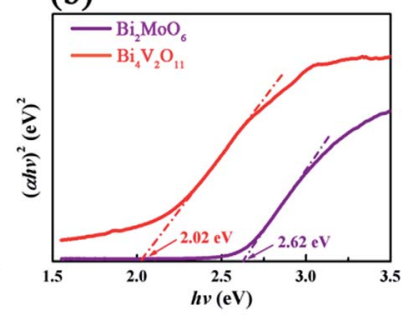

Fig. 5 The (a) UV-vis diffuse reflectance spectra (DRS) and (b) $(\alpha h \nu)^{2} v s$. $h \nu$ curves of the pristine $\mathrm{Bi}_{2} \mathrm{MoO}_{6}$ and $\mathrm{Bi}_{4} \mathrm{~V}_{2} \mathrm{O}_{11}$ samples, and the BMV-55 composite. 
(a)

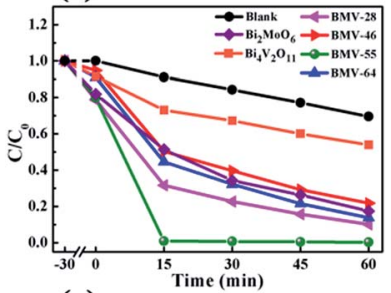

(c)

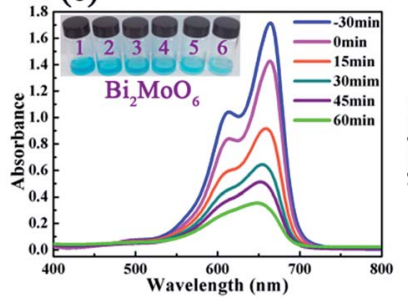

(b)

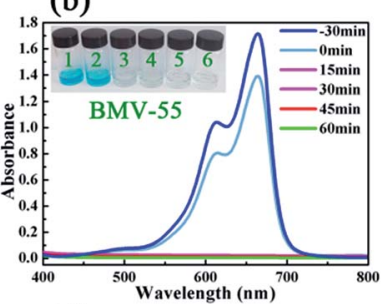

(d)

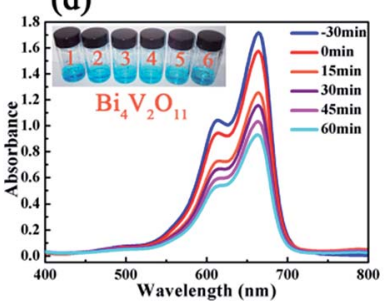

Fig. 6 (a) The photocatalytic degradation plots of $M B$ over the various photocatalysts in the presence of $\mathrm{H}_{2} \mathrm{O}_{2}$. The UV-vis absorption spectral changes observed during the degradation of $M B$ over (b) $\mathrm{BMV}-55$, (c) pristine $\mathrm{Bi}_{2} \mathrm{MoO}_{6}$ and (d) pristine $\mathrm{Bi}_{4} \mathrm{~V}_{2} \mathrm{O}_{11}$.

$\mathrm{Bi}_{2} \mathrm{MoO}_{6}$ and $\mathrm{Bi}_{4} \mathrm{~V}_{2} \mathrm{O}_{11}$ samples. To explore the effect of $\mathrm{H}_{2} \mathrm{O}_{2}$ on the degradation efficiency of $\mathrm{MB}$, the degradation experiment of $\mathrm{MB}$ without the addition of $\mathrm{H}_{2} \mathrm{O}_{2}$ was also conducted, and the result is shown in Fig. S4. $\dagger$

Obviously, the photocatalytic activity of BMV-55 in the absence of $\mathrm{H}_{2} \mathrm{O}_{2}$ is much lower than that found upon adding $\mathrm{H}_{2} \mathrm{O}_{2}$ into the system of which the degradation rate is only $75 \%$ after 90 min, indicating that $\mathrm{H}_{2} \mathrm{O}_{2}$ plays a key role in our photocatalytic reactions. To further study the photocatalytic application of the as-fabricated photocatalysts, we have also used a toxic heavy metal ion, $\mathrm{Cr}(\mathrm{vI})$, as a model pollutant, and we have conducted the photocatalytic reduction of $\mathrm{Cr}(\mathrm{vI})$ over the pristine $\mathrm{Bi}_{2} \mathrm{MoO}_{6}$ and $\mathrm{Bi}_{4} \mathrm{~V}_{2} \mathrm{O}_{11}$ samples, and the BMV-55 composite samples with the results illustrated in Fig. 7. As can be seen from the figure, the BMV-55 composite shows a distinctly enhanced photocatalytic activity for the reduction of $\mathrm{Cr}(\mathrm{vI})$ compared with pristine $\mathrm{Bi}_{2} \mathrm{MoO}_{6}$ and $\mathrm{Bi}_{4} \mathrm{~V}_{2} \mathrm{O}_{11}$, demonstrating that our heterojunction photocatalysts have a good application in wastewater purification. It is speculated that the highest

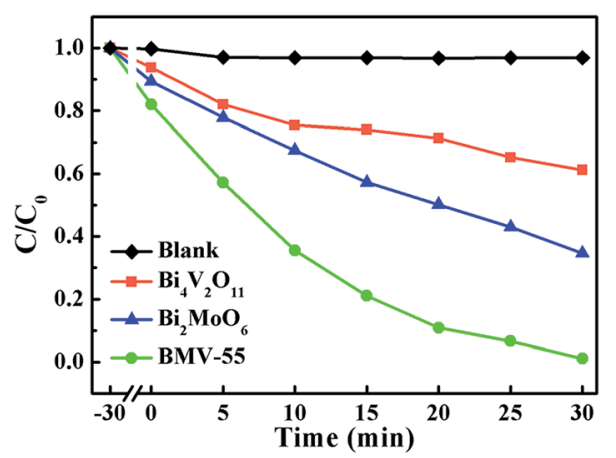

Fig. 7 The photocatalytic $\mathrm{Cr}(\mathrm{VI})$ reduction plots over pristine $\mathrm{Bi}_{2} \mathrm{MoO}_{6}$ and $\mathrm{Bi}_{4} \mathrm{~V}_{2} \mathrm{O}_{11}$, and the $\mathrm{BMV}-55$ composite samples under visible-light irradiation. activity of the BMV-55 composite could be associated with the higher separation and transport efficiency of the photo-induced carriers originating from the construction of the heterojunction between the $\mathrm{Bi}_{2} \mathrm{MoO}_{6}$ nanoflakes and $\mathrm{Bi}_{4} \mathrm{~V}_{2} \mathrm{O}_{11}$ nanocrystals. Aiming at confirming this viewpoint, two important approaches, including photoelectrochemical and photoluminescence (PL) analyses, have been used to evaluate the separation and transport efficiency of photo-induced carriers. Fig. 8 illustrates the results of the electrochemical measurements consisting of the photocurrent and electrochemical impedance spectroscopy (EIS) over the as-prepared pristine $\mathrm{Bi}_{2} \mathrm{MoO}_{6}$ and $\mathrm{Bi}_{4} \mathrm{~V}_{2} \mathrm{O}_{11}$ samples, and the BMV-55 composite, under visible irradiation. As demonstrated in Fig. 8a, the BMV55 composite exhibits a remarkably enhanced photocurrent response in striking contrast with the pristine $\mathrm{Bi}_{2} \mathrm{MoO}_{6}$ and $\mathrm{Bi}_{4} \mathrm{~V}_{2} \mathrm{O}_{11}$ samples. In detail, the photocurrent intensity of the BMV-55 composite is approximately 8- and 18-fold larger than that of pristine $\mathrm{Bi}_{2} \mathrm{MoO}_{6}$ and $\mathrm{Bi}_{4} \mathrm{~V}_{2} \mathrm{O}_{11}$, implying that the separation and transport of the photoexcited charge carriers can be effectively promoted by the construction of the heterogeneous structure by anchoring the $\mathrm{Bi}_{4} \mathrm{~V}_{2} \mathrm{O}_{11}$ nanocrystals on the $\mathrm{Bi}_{2} \mathrm{MoO}_{6}$ nanoflakes. Fig. 8b shows the EIS Nyquist plots. Apparently, the BMV-55 composite exhibits a smaller arc radius relative to that of the pristine $\mathrm{Bi}_{2} \mathrm{MoO}_{6}$ and $\mathrm{Bi}_{4} \mathrm{~V}_{2} \mathrm{O}_{11}$ samples, indicating the significantly enhanced interfacial charge carrier transport ability of the BMV-55 composite. These results can furnish the valid evidence that the BMV-55 composite possesses facilitated charge carrier separation and transport properties compared with pristine $\mathrm{Bi}_{2} \mathrm{MoO}_{6}$ and $\mathrm{Bi}_{4} \mathrm{~V}_{2} \mathrm{O}_{11}$. To shed light on the recombination rate and fluorescence lifetime of the photoinduced charge carriers, PL analysis has been performed, as shown in Fig. 9. As depicted in Fig. 9a, the BMV-55 composite exhibits a lower PL emission intensity compared with pristine $\mathrm{Bi}_{2} \mathrm{MoO}_{6}$ and $\mathrm{Bi}_{4} \mathrm{~V}_{2} \mathrm{O}_{11}$ samples, manifesting that the recombination of the photo-induced charge carriers is effectively suppressed in the $\mathrm{Bi}_{2} \mathrm{MoO}_{6} / \mathrm{Bi}_{4} \mathrm{~V}_{2} \mathrm{O}_{11}$ heterojunction. Moreover, Fig. $9 \mathrm{~b}$ presents the time-resolved fluorescence decay spectra monitored at $460 \mathrm{~nm}$ under an excitation wavelength of $345 \mathrm{~nm}$ and the corresponding fitting curve of pristine $\mathrm{Bi}_{2} \mathrm{MoO}_{6}$ and $\mathrm{Bi}_{4} \mathrm{~V}_{2} \mathrm{O}_{11}$, and the BMV-55 composite. Obviously, the decay kinetics of the BMV-55 composite are slower when compared to those of pristine $\mathrm{Bi}_{2} \mathrm{MoO}_{6}$ and $\mathrm{Bi}_{4} \mathrm{~V}_{2} \mathrm{O}_{11}$. Consequently, the radiative lifetimes are extracted by means of a reconvolution fit using a 3-exponential model (eqn (3)). ${ }^{34}$
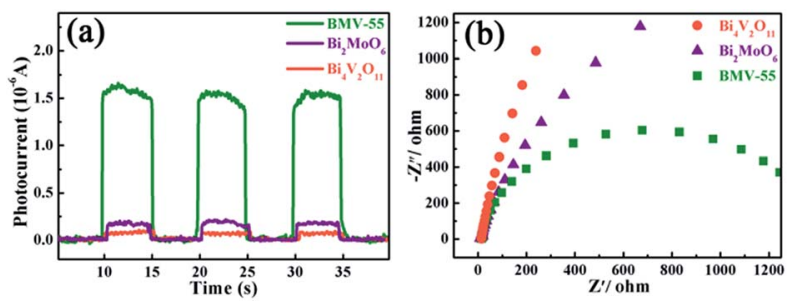

Fig. 8 The (a) transient photocurrent plots and (b) electrochemical impedance spectroscopy (EIS) Nyquist plots obtained for the pristine $\mathrm{Bi}_{2} \mathrm{MoO}_{6}$ and $\mathrm{Bi}_{4} \mathrm{~V}_{2} \mathrm{O}_{11}$, and the BMV-55 composite samples. 


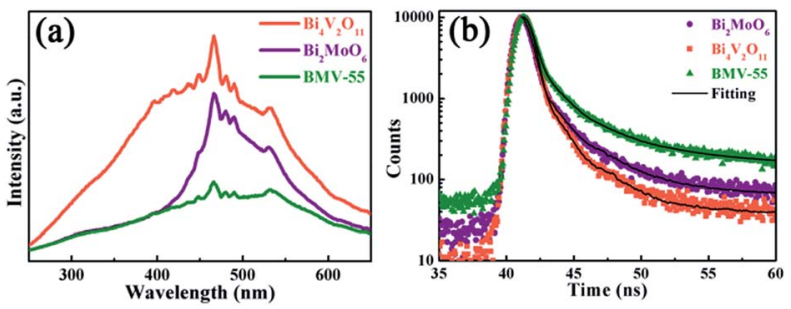

Fig. 9 (a)The PL spectra of pristine $\mathrm{Bi}_{2} \mathrm{MoO}_{6}$ and $\mathrm{Bi}_{4} \mathrm{~V}_{2} \mathrm{O}_{11}$, and the BMV- 55 composite $\left(\lambda_{\mathrm{ex}}=345 \mathrm{~nm}\right.$ ). (b) The time-resolved fluorescence decay spectra and corresponding fitting curves of pristine $\mathrm{Bi}_{2} \mathrm{MoO}_{6}$ and $\mathrm{Bi}_{4} \mathrm{~V}_{2} \mathrm{O}_{11}$, and the $\mathrm{BMV}-55$ composite.

$$
I(t)=I_{0} \sum_{i=1}^{3} B_{i} \mathrm{e}^{-t / \tau_{i}}
$$

where $t$ is the decay time after the absorption, $I(t)$ is the fluorescence intensity at time $t, I_{0}$ is the intensity at time $t=0, \tau_{i}$ is the lifetime and $B_{i}$ is the pre-exponential factor. In addition, the averaged-lifetime $\bar{\tau}$ is calculated using eqn (4). ${ }^{34}$

$$
\bar{\tau}=\sum_{i=1}^{3} B_{i} \tau_{i}^{2} / \sum_{i=1}^{3} B_{i} \tau_{i}
$$

The best fitting curve and kinetic parameters observed for pristine $\mathrm{Bi}_{2} \mathrm{MoO}_{6}$ and $\mathrm{Bi}_{4} \mathrm{~V}_{2} \mathrm{O}_{11}$, and the $\mathrm{BMV}-55$ composite are displayed in Fig. S5 in the ESI. $\dagger$ In detail, the average-lifetime of carriers in pristine $\mathrm{Bi}_{2} \mathrm{MoO}_{6}$ and $\mathrm{Bi}_{4} \mathrm{~V}_{2} \mathrm{O}_{11}$ were shortened to $c a$. 1.983 and $0.487 \mathrm{~ns}$, respectively. In contrast, the averagelifetime of the BMV-55 composite was distinctly prolonged to $7.059 \mathrm{~ns}$, indicating that the formation of the $\mathrm{Bi}_{2} \mathrm{MoO}_{6} / \mathrm{Bi}_{4} \mathrm{~V}_{2} \mathrm{O}_{11}$ heterojunction is tremendously beneficial to prolong the radiative lifetimes of the photo-induced charge carriers, and the greatly prolonged lifetime of the charge carriers could be closely related to the high separation efficiency of the charge carriers. The results of the PL spectra and time-resolved fluorescence decay spectra analysis further reveal that the BMV- 55 composite exhibits a significantly enhanced separation and transport efficiency for the photo-induced charge carriers relative to those of pristine $\mathrm{Bi}_{2} \mathrm{MoO}_{6}$ and $\mathrm{Bi}_{4} \mathrm{~V}_{2} \mathrm{O}_{11}$, which is very consistent with the results of the photoelectrochemical analysis.

From a practical point of view, the cycle stability of the photocatalysts is a very important factor in evaluating the photocatalytic performance. To evaluate the cycle stability, a cycling experiment for the photodegradation of $\mathrm{MB}$ over the BMV-55 composite upon adding $0.1 \mathrm{~mL}$ of $\mathrm{H}_{2} \mathrm{O}_{2}$ was carried out. Prior to the next cycle experiment, the previously used photocatalyst was subjected to ultrasonic cleaning with distilled water and drying at $60{ }^{\circ} \mathrm{C}$. Fig. 10 depicts the results of the recycling experiment after 4 cycles. It was be clearly seen that the photodegradation rate of MB for 15 minutes remained above $95 \%$ after 4 cycles, which indicated that the as-fabricated BMV-55 composite photocatalyst possessed good cycle stability. For the purpose of unraveling the mechanism of the enhanced photocatalytic activity of the $\mathrm{Bi}_{2} \mathrm{MoO}_{6} / \mathrm{Bi}_{4} \mathrm{~V}_{2} \mathrm{O}_{11}$ heterojunction, the energy band structures of pristine $\mathrm{Bi}_{2} \mathrm{MoO}_{6}$ and $\mathrm{Bi}_{4} \mathrm{~V}_{2} \mathrm{O}_{11}$

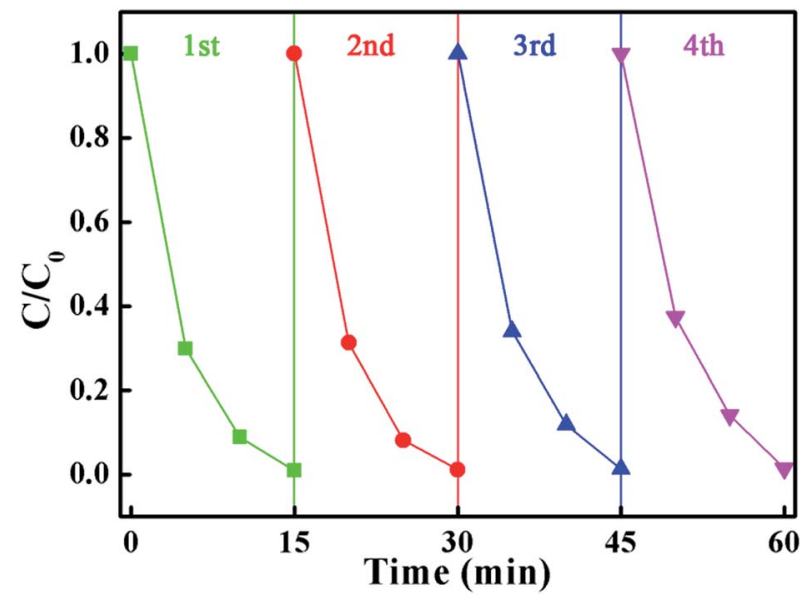

Fig. 10 The results of the recycling experiment after 4 cycles for the photodegradation of $\mathrm{MB}$ in the presence of $\mathrm{H}_{2} \mathrm{O}_{2}$ over the BMV-55 composite sample.

were investigated by determining their band gaps and flat-band potentials. Using the above UV-vis diffuse reflection spectra (DRS) analysis (Fig. 5b), the band gaps of pristine $\mathrm{Bi}_{2} \mathrm{MoO}_{6}$ and $\mathrm{Bi}_{4} \mathrm{~V}_{2} \mathrm{O}_{11}$ were determined to be 2.62 and $2.02 \mathrm{eV}$, respectively.

In addition, the flat-band potentials of pristine $\mathrm{Bi}_{2} \mathrm{MoO}_{6}$ and $\mathrm{Bi}_{4} \mathrm{~V}_{2} \mathrm{O}_{11}$ are determined via Mott-Schottky analysis, and the results are shown in Fig. 11. It can be seen that both of them show a positive slop, indicating that they are all n-type semiconductors. In addition, the flat-band potentials of pristine $\mathrm{Bi}_{2} \mathrm{MoO}_{6}$ and $\mathrm{Bi}_{4} \mathrm{~V}_{2} \mathrm{O}_{11}$ are $c a$. -0.39 and $0.26 \mathrm{~V}$, respectively, $v s$. $\mathrm{Ag} / \mathrm{AgCl}(-0.19$ and $0.46 \mathrm{~V}$ vs. NHE), which indicates that the flat-band potential of $\mathrm{Bi}_{2} \mathrm{MoO}_{6}$ is more negative than that of $\mathrm{Bi}_{4} \mathrm{~V}_{2} \mathrm{O}_{11}$ by $0.65 \mathrm{~V}$. According to the semiconductor theory, the conduction band potential $\left(E_{\mathrm{CB}}\right)$ of n-type semiconductors is very close to (0.1-0.2 $\mathrm{V}$ more negative) their flat-band potential. ${ }^{35}$ Therefore, it can be concluded that the CB position of $\mathrm{Bi}_{2} \mathrm{MoO}_{6}$ is more negative than that of $\mathrm{Bi}_{4} \mathrm{~V}_{2} \mathrm{O}_{11}$. Based on above results, possible photo-induced electron-hole pair separation and the photocatalytic degradation of $\mathrm{MB}$ mechanism over the $\mathrm{Bi}_{2} \mathrm{MoO}_{6} / \mathrm{Bi}_{4} \mathrm{~V}_{2} \mathrm{O}_{11}$ heterojunction with the assistance of $\mathrm{H}_{2} \mathrm{O}_{2}$ as an electron-trapping agent are proposed, as shown in Scheme 1. On one hand, because of the fact that the $\mathrm{CB}$ potential of $\mathrm{Bi}_{2} \mathrm{MoO}_{6}$ is more negative than that of $\mathrm{Bi}_{4} \mathrm{~V}_{2} \mathrm{O}_{11}$, the photo-induced electrons can easily migrate from the $\mathrm{CB}$ of $\mathrm{Bi}_{2} \mathrm{MoO}_{6}$ to the $\mathrm{CB}$ of $\mathrm{Bi}_{4} \mathrm{~V}_{2} \mathrm{O}_{11}$ driven by the built-in electric field at the heterostructured interface; it could be then captured
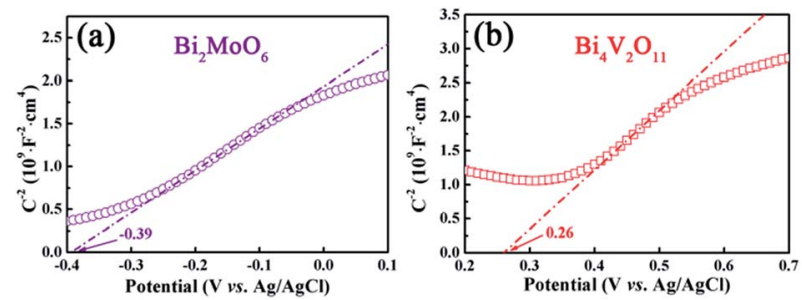

Fig. 11 The Mott-Schottky plots of (a) pristine $\mathrm{Bi}_{2} \mathrm{MoO}_{6}$ and (b) pristine $\mathrm{Bi}_{4} \mathrm{~V}_{2} \mathrm{O}_{11}$. 


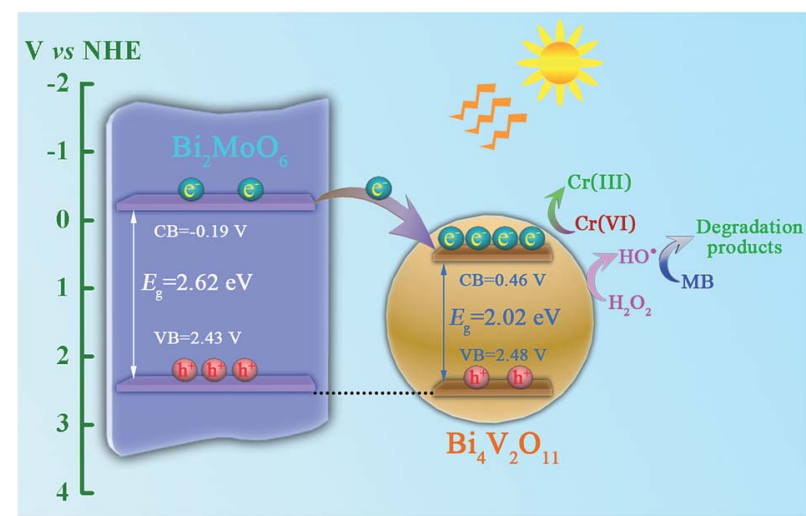

Scheme 1 A schematic illustration of the photo-induced charge carrier separation and photocatalytic reaction mechanism over the $\mathrm{Bi}_{2} \mathrm{MoO}_{6} / \mathrm{Bi}_{4} \mathrm{~V}_{2} \mathrm{O}_{11}$ heterojunction.

by $\mathrm{H}_{2} \mathrm{O}_{2}$ and reacted to generate hydroxide radicals ( $\left.{ }^{\circ} \mathrm{OH}\right)$ with strong oxidizing ability, which will completely degrade MB. On the other hand, since the VB potentials of $\mathrm{Bi}_{2} \mathrm{MoO}_{6}(2.43 \mathrm{~V})$ and $\mathrm{Bi}_{4} \mathrm{~V}_{2} \mathrm{O}_{11}(2.48 \mathrm{~V})$ are very close to each other, the migration of the photo-induced holes is very difficult, leading to the holes staying in their valence band positions. ${ }^{36}$ In this way, the rapid migration of the photo-induced electrons and the immobilization of the photo-induced holes can lead to the effective separation of the photo-induced electrons and holes over the $\mathrm{Bi}_{2} \mathrm{MoO}_{6} / \mathrm{Bi}_{4} \mathrm{~V}_{2} \mathrm{O}_{11}$ heterojunction, which ultimately results in the enhanced photocatalytic activity observed during the photodegradation of $\mathrm{MB}$.

\section{Conclusions}

In summary, a novel visible-light responsive $\mathrm{Bi}_{2} \mathrm{MoO}_{6} / \mathrm{Bi}_{4} \mathrm{~V}_{2} \mathrm{O}_{11}$ heterojunction photocatalyst with a nanosized interfacial contact has been successfully fabricated using a facile one-pot solvothermal method. The $\mathrm{Bi}_{2} \mathrm{MoO}_{6} / \mathrm{Bi}_{4} \mathrm{~V}_{2} \mathrm{O}_{11}$ heterojunctions show excellent photocatalytic $\mathrm{MB}$ degradation efficiency under visible-light illumination. In particular, the BMV-55 composite exhibits significantly enhanced photocatalytic activity during the photodegradation of $\mathrm{MB}$ and photoreduction of $\mathrm{Cr}(\mathrm{vI})$ compared with pristine $\mathrm{Bi}_{2} \mathrm{MoO}_{6}$ and $\mathrm{Bi}_{4} \mathrm{~V}_{2} \mathrm{O}_{11}$. In addition, the $\mathrm{Bi}_{2} \mathrm{MO}_{6} / \mathrm{Bi}_{4} \mathrm{~V}_{2} \mathrm{O}_{11}$ heterojunctions also display an enhanced transient photocurrent response, lower electrochemical impedance, lower PL intensity and greatly prolonged lifetime, which indicates that the photo-induced charge carriers are more effectively separated and transferred in the $\mathrm{Bi}_{2} \mathrm{MoO}_{6} /$ $\mathrm{Bi}_{4} \mathrm{~V}_{2} \mathrm{O}_{11}$ heterojunctions. The significantly enhanced photocatalytic activity and charge carrier separation effect are attributed to the formation of a heterojunction with a nanosized interfacial contact between the $\mathrm{Bi}_{2} \mathrm{MoO}_{6}$ nanoflakes and $\mathrm{Bi}_{4} \mathrm{~V}_{2} \mathrm{O}_{11}$ nanocrystals. Moreover, the $\mathrm{Bi}_{2} \mathrm{MoO}_{6} / \mathrm{Bi}_{4} \mathrm{~V}_{2} \mathrm{O}_{11}$ heterojunctions exhibit excellent cycle stability after 4 cycles. This work may be further extended to the research and development of a novel semiconductor heterojunction containing a new kind of $\mathrm{Bi}_{4} \mathrm{~V}_{2} \mathrm{O}_{11}$ photocatalyst for water purification and related applications.

\section{Conflicts of interest}

There are no conflicts to declare.

\section{Acknowledgements}

This work was financially supported by the National Nature Science Foundation of China (21501035).

\section{References}

1 S. Vadivel, D. Maruthamani, A. Habibi-Yangjeh, B. Paul, S. S. Dhar and K. Selvam, J. Colloid Interface Sci., 2016, 480, 126.

2 H. Y. Li, S. Y. Gan, H. Y. Wang, D. X. Han and L. Niu, $A d v$. Mater., 2015, 27, 6906.

3 S. Y. Dong, J. L. Feng, M. H. Fan, Y. Q. Pi, L. M. Hu, X. Han, M. L. Liu, J. Y. Sun and J. H. Sun, RSC Adv., 2015, 5, 14610.

4 J. W. Tang, Z. G. Zou and J. H. Ye, Angew. Chem., 2004, 116, 4563.

5 A. D. Paola, E. García-López, G. Marcì and L. Palmisano, J. Hazard. Mater., 2012, 211-212, 3.

6 L. Zhao, X. F. Chen, X. C. Wang, Y. J. Zhang, W. Wei, Y. H. Sun, M. Antonietti and M. M. Titirici, Adv. Mater., 2010, 22, 3317.

7 B. Huang, W. J. Yang, Y. W. Wen, B. Shan and R. Chen, ACS Appl. Mater. Interfaces, 2015, 7, 422.

8 R. A. He, S. W. Cao, P. Zhou and J. G. Yu, Chin. J. Catal., 2014, 35, 989.

9 Y. S. Xu and W. D. Zhang, Dalton Trans., 2013, 42, 1094.

10 M. Y. Zhang, C. L. Shao, J. B. Mu, X. M. Huang, Z. Y. Zhang, Z. C. Guo, P. Zhang and Y. C. Liu, J. Mater. Chem., 2012, 22, 577.

11 G. H. Tian, Y. J. Chen, W. Zhou, K. Pan, Y. Z. Dong, C. G. Tian and H. G. Fu, J. Mater. Chem., 2011, 21, 887.

12 Z. Dai, F. Qin, H. P. Zhao, J. Ding, Y. L. Liu and R. Chen, ACS Catal., 2016, 6, 3180.

13 H. P. Li, J. Y. Liu, W. G. Hou, N. Du, R. J. Zhang and X. T. Tao, Appl. Catal., B, 2014, 160-161, 89.

14 D. Yue, D. M. Chen, Z. H. Wang, H. Ding, R. L. Zong and Y. F. Zhu, Phys. Chem. Chem. Phys., 2014, 16, 26314.

15 S. Y. Wang, X. L. Yang, X. H. Zhang, X. Ding, Z. X. Yang, K. Dai and H. Chen, Appl. Surf. Sci., 2017, 391, 194.

16 T. Yan, M. Sun, H. Y. Liu, T. T. Wu, X. J. Liu, Q. Yan, W. G. Xu and B. Du, J. Alloys Compd., 2015, 634, 223.

17 M. Y. Zhang, C. L. Shao, J. B. Mu, Z. Y. Zhang, Z. C. Guo, P. Zhang and Y. C. Liu, CrystEngComm, 2012, 14, 605.

18 J. Zhao, Q. F. Lu, M. Z. Wei and C. Q. Wang, J. Alloys Compd., 2015, 646, 417.

19 Y. S. Xu, Z. J. Zhang and W. D. Zhang, Mater. Res. Bull., 2013, 48, 1420.

20 J. L. Zhang, L. S. Zhang, N. Yu, K. B. Xu, S. J. Li, H. L. Wang and J. S. Liu, RSC Adv., 2015, 5, 75081.

21 Y. Feng, X. Yan, C. B. Liu, Y. Z. Hong, L. Zhu, M. J. Zhou and W. D. Shi, Appl. Surf. Sci., 2015, 353, 87.

22 F. J. Zhang, S. F. Zhu, F. Z. Xie, J. Zhang and Z. D. Meng, Sep. Sci. Technol., 2013, 113, 1. 
23 X. F. Chen, J. B. Liu, H. Wang, Y. L. Ding, Y. X. Sun and H. Yan, J. Mater. Chem. A, 2013, 1, 877.

24 Z. Y. Jiang, Y. Y. Liu, M. M. Li, T. Jing, B. B. Huang, X. Y. Zhang, X. Y. Qin and Y. Dai, Sci. Rep., 2016, 6, 22727.

25 S. Kumar and P. D. Sahare, Nano, 2013, 8, 1350007.

26 C. D. Lv, G. Chen, J. X. Sun, Y. S. Zhou, S. Fan and C. M. Zhang, Appl. Catal., B, 2015, 179, 54.

27 Z. S. Liu, J. N. Niu, P. Z. Feng, Y. W. Sui and Y. B. Zhu, RSC $A d v .$, 2014, 4, 43399.

28 X. Yang, X. J. Lian, S. J. Liu, J. Tian, C. P. Jiang and G. Wang, Int. J. Electrochem. Sci., 2013, 8, 3721.

29 J. Di, J. X. Xia, M. X. Ji, H. P. Li, H. Xu, H. M. Li and R. Chen, Nanoscale, 2015, 7, 11433.

30 Y. T. Lu, Y. F. Pu, J. Wang, C. X. Qin, C. L. Chen and H. J. Seo, Appl. Surf. Sci., 2015, 347, 719.
31 K. K. Banger, Y. Yamashita, K. Mori, R. L. Peterson, T. Leedham, J. Rickard and H. Sirringhaus, Nat. Mater., 2011, 10, 45.

32 J. Cao, B. Y. Xu, H. L. Lin, B. D. Luo and S. F. Chen, Dalton Trans., 2012, 41, 11482.

33 W. S. D. Santos, L. D. Almeida, A. S. Afonso, M. Rodriguez, J. P. Mesquita, D. S. Monteiro, L. C. A. Oliveira, J. D. Fabris and M. C. Pereira, Appl. Catal., B, 2016, 182, 247.

34 H. L. Gao, S. C. Yan, J. J. Wang, Y. A. Huang, P. Wang, Z. S. Li and Z. G. Zou, Phys. Chem. Chem. Phys., 2013, 15, 18077.

35 C. M. Li, G. Chen, J. X. Sun, H. J. Dong, Y. Wang and C. D. Lv, Appl. Catal., B, 2014, 160-161, 383.

36 J. Su, X. X. Zou, G. D. Li, X. Wei, C. Yan, Y. N. Wang, J. Zhao, L. J. Zhou and J. S. Chen, J. Phys. Chem. C, 2011, 115, 8064. 